\title{
Applying Elements of Outdoor Education in Teacher Education Innovation
}

\author{
Mohd Taib Harun ${ }^{1} \&$ Norlena Salamuddin ${ }^{1}$ \\ ${ }^{1}$ Faculty of Education, Universiti Kebangsaan Malaysia, Selangor, Malaysia \\ Correspondence: Mohd Taib Harun, Faculty of Education, Universiti Kebangsaan Malaysia, 43600 UKM Bangi, \\ Selangor, Malaysia. Tel: 60-3-8921-6248. E-mail: mtaib@ukm.my
}

\author{
Received: August 16, 2013 Accepted: October 14, 2013 Online Published: November 28, 2013 \\ doi:10.5539/ass.v9n16p15 URL: http://dx.doi.org/10.5539/ass.v9n16p15
}

\begin{abstract}
This paper attempts to deal with the issue of developing soft skills among trainee teachers by applying the elements of outdoor education in teacher training programs. It is known that there are elements of outdoor education which were already included in the teacher training curriculum in Malaysia's Teacher Training Institutions. However, outdoor education is not a compulsory activity or subject for trainee teachers in Malaysia's universities except for those majoring in sports and recreation or physical education. However, due to the declining economic conditions, outdoor education programs at Teacher Training Institutions were the first program that was scaled down. This article attempts to identify the elements of soft skills that can be applied through a well-planned outdoor education activities. The study was conducted involving 671 samples from teacher training institutions and universities using the Life Effectiveness Questionnaire. This article focuses on four elements of soft skills namely team work, leadership ability, self-esteem and time management. The results of this study showed that outdoor education improves students' soft skills in the elements studied.
\end{abstract}

Keywords: outdoor education, teacher training, soft skills, physical education

\section{Introduction}

Outdoor education has been identified as a discipline in experiential learning (Lynch, 1993). Its approach on education is by providing physical experience as well as mental development of participants (Gair, 1997). The concept of outdoor education has been widely used in various contexts to describe a variety of experience, starting with the first school scout team camping organised in the United Kingdom by Baden-Powell in 1908. The camp was successful in increasing the number of students' enrolment in scouts and the challenging activities during camp has been successful in generating the mind, skills and experience of the scout team members. In the United States, Sharp (1895-1963) was influential in creating the outdoor education program and summer camp (Conrad, 1967). Outdoor education curriculum is often associated with 'learning school subjects outside the classroom' (Gair, 1997; Higgins \& Humberstone, 1999).

Fitzpatrick (1968) has examined 20 outdoor education programs to identify the philosophy and goals of outdoor education. He found that outdoor education can shape positive attitudes, values, and responsibility towards the environment. He stated that outdoor education is a method or process of teaching and learning through nature, community and human resources outside the classroom which can improve motivation and enrich the curriculum in a broader sense.

Implementation of outdoor education program must be dependent on the goals and objectives of the program. Priest (1990) states that the objectives of outdoor education program should be to create awareness and to form relationships with self (intrapersonal), with others (interpersonal), and the environment (ecological). Awareness of these three forms of relationship will create an environment which is conducive to the quality of life.

The Ministry of Education, Malaysia has listed outdoor education program in schools' Physical Education curriculum. This is in contrasts with the curriculum in teacher training institutions and universities whereby outdoor education is not incorporated in their curriculum. At these higher education institutions, outdoor education stands on its own. Outdoor activities like camping, recreational activities, and field visits were carried out as extra-curricular activities in higher education institutions. In order to develop the potentials in all students, activities that use the approach of learning through experience should be implemented as part of the curriculum, 
with the help of experienced instructors and facilitators.

Mohd Nor Che Noh (1982) uses personality tests and found that students whom took part in outdoor activities were more dominant in terms of strength and endurance, social and self-confidence, aggressiveness, leadership, anxiety control, positive attitude and resistance to physical illness than those who did not participate. According to Faridah Karim (2004) co-curricular activities are as important as the curriculum for behavioural changes with regards to the cognitive, psychomotor and affective domains.

Promoting learning in the natural environment outside the classroom puts emphasis on reality. Outdoor education will shape and improve the classroom experience (Vasudevan, 1991). Outdoor education is comprehensive and covers the field of psychology, sociology, pedagogy, medicine, health and recreation. Many people do not realize the strength of the concept of outdoor education because it is new and high-risk. Furthermore, since it is a non-examination subject, students are less exposed to it. The outdoor education participants sometimes do not get any input other than merely enjoying the activities in the program. This is because the activities were planned nonchalantly and as a result students' interest in the program dwindles.

One way to achieve Malaysia's Vision 2020 is to accelerate the development of the cognitive, affective, social and psychomotor domains in the education system. Therefore, outdoor education programs need to be restructured to meet the needs of these domains such as improving problem-solving ability, psychomotor ability and sensitivity to the self which will develop confidence and positive self-concept. Abdul Alim Abdul Rahim (1994) states that activities conducted beyond the classroom will create a more conducive school environment. These activities add significance and support the curricula in creating a better student both in academia and in extra-curricular areas. This is consistent with the philosophy advocated by the Outdoor Education Curriculum Development Centre (1998) which states that:

\section{Nature is a living laboratory which is a rich source of knowledge. It can be integrated with practices that can enrich the experience and foster the values for healthy individuals to produce mental, spiritual and physical assimilation thus establishes integrity among the people towards national unity.}

Outdoor education program is considered very appropriate to the educational system at this time because the main objectives of outdoor education is centred on three domains of psychomotor, cognitive and affective domains (Harmon, 1978; Hattie, Marsh, Neil \& Richard, 1997).Psychomotor domain is the mastery of specific skills such as abseiling, kayaking and mountain climbing activities which involve mastery of technique. On the other hand, cognitive domain focuses on the knowledge, facts and problem solving skills; while the affective domain focuses on developing attitudes, values and appreciation of issues, including attitudes towards the environment.

The importance and benefits of outdoor education programs includes expanding individuals' potential, knowledge, and improving and sharpening the intellectual ability of students. Teaching in the classroom is focused on the theory and understanding of concepts, while the outdoor education's role is to develop students' talents and potential. Mohamad Nor Che Noh (1985) recommended that all students, regardless of existing limitations, should be given the opportunity to participate based on their interest and ability in order for them to enjoy the benefits of such participation. This article aims to identify whether there is instillation of soft skills among the participants who attended outdoor education program.

\section{Methodology}

\subsection{Study Design}

This study uses a quasi experimental design to test the elements of soft skills that can be applied through outdoor education program. Analyses conducted investigates the relationship between the variables, tests the hypotheses and form generalizations on the applicability of outdoor education program in inculcating four aspects of soft skills. Quasi-experimental design was chosen for this study because it uses already formed samples. Furthermore, this study also involved an intervention program to see the changes in the sample.

\subsection{The Sample}

The sample consisted of 671 students who were pursuing courses in institutions of higher education in Malaysia. The sample consists of trainee teachers in physical education or sports and recreation program as the experimental group, while the students that are not involved in the two programs were the control group. Students of physical education and sports and recreation were selected because they were involved in outdoor education as part of their course structure. 


\subsection{Procedure}

Life Effectiveness Questionnaires were administered twice during the study; in the pre-test and post test. In the pre-test, respondents were given questionnaires to answer a week before their outdoor education program. Once respondents completed the outdoor education program which lasted for five days and four nights, they were given the post test.

The experimental group was divided into four based on the sequence of activities in the outdoor education program. Table 1 describes the treatment received by the experimental groups.

Table 1. Treatments received by the experimental group

\begin{tabular}{ccc}
\hline Group & Name & Type of Treatment \\
\hline Control & Control & None \\
Experiment & Module 1 & All low-risk activities \\
& Module 2 & Sequence of activities from low to high risk \\
& Module 3 & No significant sequence \\
& Module 4 & Sequence of activities from high risk to low risk \\
\hline
\end{tabular}

\subsection{The Instruments}

The instrument used was adapted from the Life Effectiveness Questionnaire (Neill, 1997). Questions used focuses on those related to the four constructs that was observed namely teamwork, leadership skills, confidence and time management. Respondents were also required to provide some background information such as gender, age and identity card number so that the information obtained can be compared, but still maintain the confidentiality of the samples.

\subsection{Data Analysis}

Data were analyzed using descriptive and inferential statistics. The inferential analyses used were the $t$ tests, and Cohen's D. The $t$ test was use to determine the difference between the control and treatment groups. Cohen's D was used to determine the contribution of outdoor education program in inculcating soft skills of the individual.

\section{The Findings}

\subsection{Pilot Study}

The questionnaire used was pilot tested to see the validity and reliability of the items. Table 2 shows the results of reliability analysis for the four constructs.

Table 2. Cronbach $\alpha$ values for the constructs

\begin{tabular}{cc}
\hline Constructs & Cronbach $\boldsymbol{\alpha}$ values \\
\hline Teamwork & 0.73 \\
Leadership ability & 0.85 \\
Confidence & 0.86 \\
Time management & 0.85 \\
\hline
\end{tabular}

Results of the reliability analysis showed that the Cronbach $\alpha$ value obtained is between 0.73 and 0.86 . Comparing this results with those done by Neill (2002), the $\alpha$ value were similar. Thus, the questions used were reliable to be used in the local context.

\subsection{Descriptive Statistics}

A total of 671 students made up the sample for this study which comprises of 249 male (37.1\%) and 422 female $(62.9 \%)$ students. The age of the respondents was categorized into seven categories. In addition the respondents were divided into two main groups namely the experimental group and the control group. The experimental group were further divided into four subgroups based on the sequence of outdoor education programs that they 
were exposed to. Table 3 shows the analysis of the respondents' demographic data.

Table 3. Analysis of respondents' demographic data

\begin{tabular}{|c|c|c|c|}
\hline \multicolumn{2}{|c|}{ Demographic factors } & \multirow{2}{*}{$\begin{array}{l}\mathbf{n} \\
249\end{array}$} & \multirow{2}{*}{$\begin{array}{l}\% \\
37.1\end{array}$} \\
\hline Gender & Male & & \\
\hline Gender & Female & 422 & 62.9 \\
\hline \multirow{7}{*}{ Age } & $19.1-21.0$ & 92 & 13.7 \\
\hline & $21.1-23.0$ & 111 & 16.5 \\
\hline & $23.1-25.0$ & 169 & 25.2 \\
\hline & $25.1-27.0$ & 169 & 25.2 \\
\hline & $27.1-29.0$ & 61 & 9.1 \\
\hline & $28.1-34.0$ & 49 & 7.3 \\
\hline & $34.1-40.0$ & 20 & 3.0 \\
\hline \multirow{2}{*}{ Exposure } & Received exposure to outdoor education (Experimental) & 590 & 87.9 \\
\hline & Were not exposure to outdoor education (Control) & 81 & 12.1 \\
\hline
\end{tabular}

\subsection{Inferential Statistics}

\subsubsection{Effects of Outdoor Education on Soft Skills Development}

To test the first null hypothesis which suggests that outdoor education program is not effective in soft skills development, a t test analysis was conducted. Table 4 shows the results of the $t$ test.

Table 4. Effects of outdoor education program on soft skills development

\begin{tabular}{llllll}
\hline Groups & $\mathbf{n}$ & Pre-test scores & Post-test scores & df & t \\
\hline Treatment & 590 & $121.40(19.53)$ & $280.65(22.90)$ & & \\
Control & 81 & 129.64 & 122.38 & 669 & $72.84 *$ \\
& & $(8.77)$ & $(9.58)$ & & \\
\hline
\end{tabular}

$*<0.05$

The $t$ test showed that there is a significant difference between the experimental group and the control group, where $\mathrm{t}(669)=72.84, \mathrm{k}<0.05$. This means that there is a difference in soft skills development after the sample was exposed to outdoor education program. Therefore, the null hypothesis which states that the outdoor education program has no impact on individual soft skills was rejected. To conclude, outdoor education program does have a significant impact on soft skills development.

Since there is a significant effect on soft skills development after going through the outdoor education program, further analysis were conducted to see which constructs improve more significantly than others and the contributions of these constructs on the participants' soft skills development. Table 5 shows the analysis of the soft skill constructs and contributions of the components. 
Table 5. The test was to see the components of soft skills and the contribution of these components

\begin{tabular}{lllllll}
\hline Constructs & Group & Pre-test Scores & Post-test scores & df & t & Cohen's d \\
\hline Teamwork & Treatment & $10.38(5.23)$ & $20.42(2.36)$ & \multirow{2}{*}{669} & $24.71 *$ & $12: 34$ \\
& Control & $12.01(3.04)$ & $10.52(1.96)$ & & & \\
Leadership ability & Treatment & $6.93(2.37)$ & $19.24(7.33)$ & \multirow{2}{*}{669} & $42.79 *$ & 0.60 \\
& Control & $7.80(1.58)$ & $7.33(1.69)$ & & & \\
Confidence & Treatment & $7.99(2.34)$ & $20.32(2.30)$ & & & \\
& Control & $7.76(2.53)$ & $7.52(1.64)$ & & $37.07 *$ & $12: 52$ \\
Time management & Treatment & $6.94(2.40)$ & $19.23(2.36)$ & & & \\
& Control & $7.14(1.83)$ & $6.95(2.02)$ & 669 & $38.69 *$ & $12: 54$ \\
\hline
\end{tabular}

$*<0.05$

The $t$ test analysis between the treatment group and the control group showed a significant effect for all constructs. Results showed that there was a significant effect for the construct of teamwork [t $(669)=24.71, \mathrm{k}$ $<0.05$ ], leadership ability [ $\mathrm{t}(669)=42.79, \mathrm{k}<0.05$ ], confidence [ $\mathrm{t}(669)=37.07, \mathrm{k}<0.05]$ and time management $[\mathrm{t}(669)=38.69, \mathrm{k}<0.05]$.

In relation to this, an analysis of the effect size of the contribution of outdoor education program was done. Cohen's $d$ analysis was used whereby it states that the value of 0 indicates no contribution, while the value of 0.1 - 0.2 is considered as a small contribution, a value of $0.3-0.5$ is considered as moderate contribution, while values above 0.6 indicate a relatively large effect size. Referring to Table 5 , the outdoor education program contributed modestly by about $34 \%$ for the component of teamwork, $53 \%$ for the components of self-confidence and $54 \%$ for the time management component. While for the component of leadership ability, the outdoor education program provides a relatively large contribution of $60 \%$.

\subsubsection{Effects of Outdoor Education and Demographic Factors on Soft Skills}

Inferential analysis was used to answer the question of whether outdoor education program and demographic factors influences changes in soft skills development. This analysis test the null hypothesis that states that exposure to outdoor education program and demographic factors does not affect the changes in soft skills. For this hypothesis, separate analyzes using multiple regression statistics with two sets of predictors were conducted. The first set of predictors that is exposure to the outdoor education program while the second set of predictors were gender. Table 6 shows the correlation factor for soft skills, exposure to the program and gender.

Table 6. Correlation factor for soft skills, exposure to the program and gender

\begin{tabular}{|c|c|c|c|}
\hline Constructs & Mean & $\mathrm{SD}$ & $r_{p}$ \\
\hline \multirow[t]{2}{*}{ Teamwork } & 2.88 & 2.12 & Exposure $=-0.59^{*}$ \\
\hline & & & Gender $=-0.01$ \\
\hline \multirow[t]{2}{*}{ Leadership ability } & 3.59 & 1.66 & Exposure $=-0.84^{*}$ \\
\hline & & & Gender $=-0.01$ \\
\hline \multirow[t]{2}{*}{ Self-esteem } & 3.60 & 1.59 & Exposure $=-0.86^{*}$ \\
\hline & & & Gender $=0.03$ \\
\hline \multirow[t]{2}{*}{ Time management } & 3.60 & 1.65 & Exposure $=-0.82 *$ \\
\hline & & & Gender $=-0.04$ \\
\hline
\end{tabular}

Table 6 shows that predictors of exposure to outdoor education program has a significant impact on individual soft skills. Analysis conducted gave the following results: teamwork $(r=-0.59$ pexposure, $p<0.05)$, leadership ability $\left(r=-0.84 p_{\text {exposure, }} \mathrm{p}<0.05\right)$, confidence $\left(\mathrm{r}=-0.86 \mathrm{p}_{\text {exposure, }} \mathrm{p}<0.05\right)$ and time management $(\mathrm{r}=-0.82$ $\mathrm{p}_{\text {exposure, }} \mathrm{p}<0.05$. Meanwhile, the gender of participants is not a good predictor for soft skills development as the results were all not significant. 
Further analysis using multiple regression was carried out to determine which predictors has an impact on the participants' soft skill development. Table 7 shows the results of the multiple regression analysis.

Table 7. Multiple regression analysis of constructs (criteria) by gender and exposure to outdoor education program (predictor factors)

\begin{tabular}{llcccccc}
\hline Constructs & Predictive factors & $\mathrm{R}$ & $\mathrm{R}^{2}$ & $\mathrm{Adj} . \mathrm{R}^{2}$ & $\mathrm{R}^{2}$ change & F change & $\mathrm{df}$ \\
\hline Teamwork & Exposure & 0.59 & 0.35 & 0.35 & 0.35 & $359.96^{*}$ & 1,669 \\
& Gender & 0.02 & 0.01 & -0.01 & 0.01 & 0.25 & 1,669 \\
& Exposure * Gender & 0.59 & 0.35 & 0.35 & 0.01 & 0.31 & 1,668 \\
Leadership ability & Exposure & 0.84 & 0.70 & 0.70 & 0.70 & $1554.54^{*}$ & 1,669 \\
& Gender & 0.03 & 0.01 & -0.01 & 0.01 & 0.61 & 1,669 \\
Confidence & Exposure * Gender & 0.84 & 0.70 & 0.70 & 0.01 & 2.41 & 1,668 \\
& Exposure & 0.86 & 0.74 & 0.73 & 0.74 & $1862.43^{*}$ & 1,669 \\
& Gender & 0.01 & 0.01 & -0.01 & 0.01 & 0.01 & 1,669 \\
& Exposure * Gender & 0.86 & 0.74 & 0.74 & 0.01 & 0.01 & 1,668 \\
& 0.82 & 0.68 & 0.68 & 0.68 & $1401.84^{*}$ & 1,669 \\
& Exposure & 0.01 & 0.01 & -0.01 & 0.01 & 0.01 & 1,669 \\
& Gender & 0.82 & 0.68 & 0.68 & 0.01 & 0.01 & 1,668 \\
\hline
\end{tabular}

Two multiple regression analysis were performed to see whether exposure to outdoor education and gender can predict changes in soft skills development. Regression equations show that exposure to outdoor education program provides a significant effect for all constructs of soft skills (teamwork: $\mathrm{R}^{2}=0.35, \mathrm{~F}(1,669)=359.96$, $\mathrm{p}$ $<0.05$; leadership ability: $\mathrm{R}^{2}=0.70, \mathrm{~F}(1,669)=1554.54, \mathrm{p}<0.05$; confidence: $\mathrm{R}^{2}=0.74, \mathrm{~F}(1,669)=1862.43$, $\mathrm{p}<0.05$; time management: $\left.\mathrm{R}^{2}=0.68, \mathrm{~F}(1,669)=1401.84, \mathrm{p}<0.05\right)$. Meanwhile, the predictive factors of gender and interaction between the two predictive factors were not significant. Based on these results, exposure to outdoor education program is a better predictor to assess changes in soft skills.

\section{Summary}

In conjunction with this study, several conclusions were obtained. The first conclusion is that participation in outdoor education programs provides benefits in terms of changes in soft skills of students in institutions of higher education. Although this study cannot be generalized to all students in Malaysia, but the findings and conclusions made can be generalized to all teenagers who are in educational institutions. The study also proves that there are positive changes in four constructs of soft skills. This finding is consistent with the findings by other researchers such as Neill (2003) and Stenger (1994). This study also showed that demographic factors do not provide significant differences in the development of soft skills. Thus, it can be concluded that outdoor education programs can be used both for boys and girls alike. These findings are consistent with previous findings made by Acuff (1976) and Neill (2000) on soft skills, life effectiveness and the influence of sequencing in outdoor education activities.

\section{References}

Acuff, D. S. (1976). The effect of an outdoor education experience on the general and Intercultural anxiety of Anglo and Black sixth graders. PhD dissertation. University of Southern California, USA.

Alim, A. R. A. (1994). Teacher Education Series: Management co. London: Cavendish Publishing Ltd.

Conrad, L. H. (1967). LB Sharp's philosophy of education. Journal of Outdoor Education, 1(3), 6-8.

Curriculum Development Centre. Ministry of Education Malaysia. (1998). Physical Education Syllabus. Kuala Lumpur: Department of State Publication.

Fitzpatrick, C. N. (1968). Philosophy and Goals for outdoor education. PhD dissertation. Colorado State College, $\mathrm{CO}$.

Gair, N. P. (1997). Outdoor education. London, UK: Cassell. 
Harmon, P. (1978). The measurement of Affective domain. Journal of Physical Education and Dance, 67(8), 41-44.

Hattie, J. A., Marsh, H. W., Neill, J. T., \& Richard, G. E. (1997). Adventure Education and Outward Bound: Out-of-class experience That has a Lasting effect. Review of Educational Research, 43-87. http://dx.doi.org/10.3102/00346543067001043

Higgins, P., \& Humberstone, B. (1999). Outdoor education and experiential learning in the UK. Germany: Verlag Erlebnispadagogik-Luneberg.

Karim, F. (2004). Bangsa Malaysia: A reality in community patterns. Article presented at the Congress of Education, Malaysia, Universiti Kebangsaan Malaysia, Bangi, Selangor. 3 to 5 August 2004.

Lynch, P. (1993). Outdoor education: Semantics and definitions. Christchurch, New Zealand: Lincoln University.

Neill, J. T. (1997). Gender: How does it effect the outdoor education experience? In Catalysts for change: $10^{\text {th }}$ National Outdoor Education Conference Proceedings. January 20 to 24, pp. 183-192. Sydney, Australia: The Outdoor Professionals.

Neill, J. T. (2000). The Life Effectiveness Questionnaire: A tool for measuring change. ACT, Australia: University of Canberra.

Neill, J. T. (2002). Meta-analytic research on the outcomes of outdoor education. Paper presented at 6th Biennial Coalition for Education in the Outdoors Research Symposium, Bradford Woods, IN.

Neill, J. T. (2003). Reviewing and benchmarking adventure therapy outcomes: Applications of meta-analysis. Retrieved from http://www.wilderdom.com/adventuretherapy

Noh, N. C. M. (1982). A study on the effect of participation in sports and some social psychological variables on adjustments and academic Achievement. Washington, DC: National University of Malaysia.

Noh, N. C. M. (1985). Some considerations in the management and administration of co-curricular programs in schools. Journal of the Ministry of Education Malaysia, 67.

Priest, S. (1990). The semantics of outdoor education. In J. C. Miles, \& S. Priest (Eds.), Adventure education. State College, PA: Venture Publishing.

Sharp, L. B. (1930). Education and the summer camp. New York, NY: Bureau of Publications, Teachers College, Columbia University.

Stenger, T. L. (2001). Sequence of resident outdoor adventure-based education programs and middle school students' perceptions of life effectiveness. PhD dissertation. Oklahoma State University.

Vasudevan Arasoo, T. (1991). Extra-curricular activities, supervision and administration. New York: Oxford University Press.

\section{Copyrights}

Copyright for this article is retained by the author(s), with first publication rights granted to the journal.

This is an open-access article distributed under the terms and conditions of the Creative Commons Attribution license (http://creativecommons.org/licenses/by/3.0/). 